This document is the Accepted Manuscript version of a Published Work that appeared in final form in:

Jørgensen S.L., Termansen M., Pascual U. 2020. Natural insurance as condition for market insurance: Climate change adaptation in agriculture. ECOLOGICAL ECONOMICS. 169. DOI (10.1016/j.ecolecon.2019.106489).

(C) 2019 Published by Elsevier B.V.

This manuscript version is made available under the CC-BY-NC-ND 3.0 license http://creativecommons.org/licenses/by-nc-nd/3.0/

\title{
1 Natural insurance as condition for market insurance: Climate 2 change adaptation in agriculture
}

3

4 Abstract

5 This paper focuses on the potential use of insurance as a climate change adaptation mechanism

6 in agriculture. We analyse the attractiveness of a climate risk insurance scheme and the choices

7 farmers face between adaptation via farm management practices and purchase of crop insurance in the market. A choice experiment is used to reveal Danish farmers' preferences regarding an insurance contract where adoption of land management practices to improve soil sustainability is conditional for obtaining insurance cover in the market. Results indicate that in general arable farmers and farmers with low soil quality who have experienced crop damages in the past are more likely to purchase such conditional insurance. Farmers with good quality soils, who perceive that they have already adapted their practices to climatic risks and who have not experienced losses due to adverse climatic events in the past are less willing to purchase insurance. The paper contributes to the limited knowledge on preferences for climate risk-related insurance in agricultural systems in general, and in Europe in particular.

\section{Key words: natural insurance, market insurance, yield insurance, index insurance, choice} experiments, latent class, risk mitigation, sustainable soil management 


\section{Introduction}

2 The more extreme weather events being experienced in recent years and potential increases in

3 the frequency and intensity of future weather extremes pose a significant risks to farmers' 4 agricultural production and incomes (Bielza et al., 2008; Ciscar et al 2018; Vogel et al 2018; 5 Brower, 2019). Heavy rain or drought can cause large production losses if they occur when crops are vulnerable to such weather extremes. To avoid such losses, farmers may adapt to changes in climate by introducing less sensitive crops, investing in more robust agro-ecological management or taking land out of production (Wood et al, 2017). Farmers can choose to mitigate climate-related risk by investing in insurance and thus redistributing income to secure a given level of income in hazardous states (Baumgärtner \& Quaas, 2010; Baumgärtner \& Strunz, 2014; Strunz \& Baumgärtner, 2010; Strunz, 2011; Pascual et al 2015). Agricultural insurance markets have a long tradition in developed countries, such as in the US by offering yield insurance to farmers, although this is not as widespread in Europe (Santeramo and Ramsey, 2017). In the US famrers can generally insure against yield (or revenue) losses from natural disasters (drought, hail, insects, frost, etc.) and against falling prices (Miranda and Vedenov 2001; ARMS 2010). In Europe, Spain and France have attempted at establishing weather-indexed insurance but with not much success (Santeramo and Ramsey, 2017). There has also been an attempt to introduce insurance against adverse weather events into the Danish market (Jørgensen, 2015).

But the effects of standard agricultural insurance products can have unintended effects. The literature points towards the fact that agricultural insurance tends to negatively affect the environment given the reduction in self protection behaviour through a decrease of the effort towards sustainable land management. This is a form of moral hazard. Baumgärtner and Quaas (2007) and Quaas and Baumgärtner (2008) show this theoretically, while Horowitz and Lichtenberg (1993) and $\mathrm{Wu}(1999)$ test the hypothesis empirically and find that farmers tend to undertake riskier and adopt more intensive agricultural practices (e.g. they use more fertilisers, pesticides, etc.) when they purchase agricultural insurance. The link between insurance and environmental impact in agrarian systems requires understanding how insurance mitigates the influence of uncertainty on a farmer's well-being (Baumgärtner \& Strunz, 2014).

30 For a farmer this can be achieved in ways other than through purchasing conventional insurance. Natural insurance (NI) works as the market insurance: the land manager redistributes income, by managing natural capital, towards securing income flows in hazardous states 
1 resilience and reduce the risk of undesirable outcomes, i.e. it will keep the ecosystem in a desired and productive domain (Baumgärtner \& Strunz, 2014). In other words, a wellfunctioning agroecosystem will act as NI by reducing farmers' risk (Crocker, Kask, \& Shogren, 1998). This is also sometimes called self-insurance (Becker et al, 1972; Pascual et al., 2015). The cost of NI is the economic loss resulting from employing land management restrictions and foregoing economic opportunities. An examples of NI is the construction of wetlands which reduces the risk of production loss on the neighbouring fields by channelling water away from agricultural fields. The current special issue also offers examples of the potential use of natural insurance in sectors other than agriculture (Paavola and Primmer, this issue). According to Quaas and Baumgärtner (2008) and Baumgärtner and Quaas (2010) NI and market insurance (MI) are likely to be substitutes in certain cases; if, for example, yield insurance is being offered by a commercial insurer, the farmer may buy that insurance instead of practising NI. Therefore, availability of MI can reduce demand of NI through competition, and thereby may negatively agroecosystem resilience attributes, especially under short-term low-cost MI (Becker et al., 1972). The problem arises when choosing to invest in MI the farmer foregoes the option to invest in natural capital, thereby creating a typical problem of moral hazard. Further, it is plausible that the degradation of natural capital which may act as NI, implies incurring in a higher cost of undertaking NI in the longer term if the marginal cost of restoration of natural capital increases over time, thereby making investments in NI becoming less attractive as farmers further rely on MI.

This paper studies the potential insurance choices confronted by commercial farmers as a climate change adaptation mechanism. We analyse the attractiveness for farmers in voluntarily entering into climate risk insurance schemes in cases where such schemes are conditional on investing in NI (as a way to minimize moral haard) through adoption of soil management actions. Using a case study from Denmark, a choice experiment is conducted to reveal how farmers perceive the risk of crop damage from climate change and the extent to which they perceive adoption of conditional insurance schemes to be beneficial. The choice experiment is based on a representative sample of 593 Danish farmers and focuses on their choice between purchasing different market insurance products with varying insurance coverage, costs (insurance premiums) and conditionality measures (in the form of undertaking different sustainable soils practices). To the best of our knowledge, we conduct the first study to analyse the preferences of farmers of entering into an insurance scheme to adapt to climate change under conditional natural insurance investments. 
1 The next section gives an overview of some of the challenges related to the introduction of market insurance in the agricultural sector. Section 3 presents the Danish case study including the hypothetical insurance scheme used in the choice experiment and the modelling approach. The results of the survey are presented in section 4, and section 5 discusses the results and concludes.

\section{2. Market insurance of agricultural production}

7 Several well-known obstacles exist to achieve an efficient insurance market. The main challenges are the problems related to asymmetrical information such as adverse selection and moral hazard. These arise because farmers have an incentive to strategically withhold information from the insurer. Firstly, farmers facing high risk of loss are more likely to seek insurance (adverse selection). Secondly, farmers might be tempted to behave in more risky ways when insured (moral hazard). The challenges can be addressed in several ways, for example through type-specific insurance, area yield insurance and weather insurance (Glauber 2004; Rasmussen 2008).

For type-specific insurance, the insurer identifies different types of farmers and then designs individual contracts for each of those types. Each type of farmer will then be offered a contract designed for the risk characterising their type of farming. This type of contract leads to relatively high administrative costs as it requires detailed information about the farmer and farm operation in order to design an optimal contract. To overcome this, compensation under an "area yield insurance" has been proposed (Miranda 1991), as this would not depend on the individual land manager's yield, but on the average yield in a given land area. Thereby, the farmer will only be compensated if there is a general loss in the area. Since there is nothing to gain from undertaking more risky behaviour, the problem of moral hazard is no longer a key issue for the insurer. Additionally, the farmer would not have a motivation to withhold information, since the insurance contract attributes and compensation holds for all the farms in the area. Adverse selection is also minimised since information on average yield in an area is generally more reliable than information on individual farm yield (Linnerooth-Bayer and Mechler 2015). Another form of insurance is related to weather-indexed insurance. It works in a similar way: the farmer will only be compensated if a bad weather event is documented. This implies that the incentive to behave in a more risky manner is reduced, since compensation is not based on the farmer's yield but on exogenous weather events; hence the farmer still has an incentive to maintain soil productivity. Nevertheless, irrespective of the type of insurance 
1 farmers may still reduce adoption of sustainable practices (decline in Natiral Insurance) in order

2 to maximize short term yields at the cost of long run productivity and system resilience.

3 Both area yield and weather insurance are index-based schemes and rely on a simple insurance mechanisms: everybody pays the same premium, there is no need for the farmer to prove the loss, and everybody gets the same compensation. The effectiveness of index-based insurance in reducing risk depends on how well the actual yield correlates with the index (Glauber 2004).

7 For weather insurance to be effective, a high density of weather stations is required. Otherwise, the variations in the weather-index will not reflect the variation in risks between farms. Organisations such as the World Bank promotes weather insurance in many developing countries (Tadesse et al., 2017) although there are still scant rigorous evaluations of such insurance schemes due to lack of data (Jansen and Barrett, 2017).

12 There are indications that while index-based insurance can help reduce moral hazard, adverse selection and administrative costs, it also creates new problems. One is the displacement of risk unevenly between groups of farmers when we understand as risk being unevenly "produced" and "displaced" through socio-ecological processes, thereby providing benefits and security to some by transferring risks to others (Taylor 2016). Another related problem, arises since compensation is made independently of individual realised damages and thus can cause significant livelihood challenges and not give farmers the income stability they seek to obtain through insurance. On the one hand, if risks are low, the farmer will be further encouraged to maintain a sustainable and healthy farmland: the farmer will be compensated if bad weather occurs, and if the soil is well managed and no loss occurs, an "extra income" is earned. On the other hand, if the compensation payments do not cover the effort and costs of managing farmland sustainably, the farmer has no incentive to invest in natural insurance. This means that the capacity of index-based insurance to encourage natural insurance for instance by initiating sustainable agricultural management depends on the relative size and spatial and temporal distribution of the gains and losses. It can be noted that farmers who do not invest in the adoption of appropriate land management practices may be shifting the negative consequences of such behaviour to other farmers (e.g, via hydrological connectivity, soil erosion, etc.) now and into the future, thus making this a longer term sustainability issue.

Private insurers, farmers and regulators face different needs and challenges. While moral hazard and adverse selection tend to be seen as the problems faced by the private insurer, from a societal perspective (that is, from the regulator's perspective) such problems are also relevant 
1 as private insurance markets may involves a risk of increased degradation of agricultural land or disinvestment in natural insurance which can be seen as a "public bad". From the farmers' perspective the choice between purchasing insurance or not purchaising it depends on perceived risks associated with extreme climate events, the level of insurance premium, and farm productivity, among others.

6 There is a scant literature that analyzes farmers' preferences for insurance using stated 7 preference methods. Sherrick et al. (2003) analysed US farmers' preferences with a conjoint analyse. They found that contract flexibility is the most important attribute to farmers, indicating that farmers would like greater freedom in selecting which areas to insure. With flexible contracts the farmers seems to prefer revenue insurance over yield insurance, while they put more weight on low coverage/cost/frequency if they are presented with an inflexible contract. Nganje et al. (2004) also looked at farmers' preferences for insurance in terms of crop insurance and found that coverage level, insurance type, and premium size affect choice of crop insurance. More recently, Tadesse et al (2017) applied a choice experiment in Ethiopia to test the advantage of combining cash premiums and labour application (e.g., for tree planting to retain soil) as a work-for-insurance scheme targeted at poor farmers who cannot afford to pay full insurance premiums in cash.

This paper is an empirical analysis to shed light on the preferences farmers have to invest in market insurance, and how such schemes might be designed to promote environmentally appropriate land management, i.e., to not compromise natural insurance investments. We present a new kind of insurance scheme for crop yield based on an index insurance which is contingent on farmers investing in sustainable soil management. That is, in order to receive compensation by the insurer the farmer must fulfil certain soil management requirements (akin to investment in natural insurance), for example by ensuring green fields in winter, growing catch crops, practicing no-tillage or undertaking other measures that enhance the sustainability of the soil. By exposing farmers to different insurance contracts by the regulator, with varying combinations of price premiums, compensation terms (yield or weather index schemes, level of excess) and soil management requirements.

30 We test this insurance scheme in a hypothetical setting building on the attempts to introduce weather insurance into the Danish market by CelsiusPro insurance company in collaboration with SEGES (Danish Knowledge Centre for Agriculture) around 2012. CelsiusPro sells 
1 weather certificates for weather-dependent industries, such as the construction and agricultural sector, worldwide. Their business is therefore based on risk pooling. ${ }^{1}$

\section{Methods - developing a conditional insurance scheme for Danish} farmers

In order to analyse the uptake of a climate risk insurance scheme in practice, a questionnaire was designed and responses collected about the charactersitics of individual farmers who expect to be affected by adverse climatic events. The questionnaire was an input to a choice experiment to analyse farmers' preferences for a hypothetical insurance scheme with requirements for also investing in natural insurance by improving soil management. (Questionnaire can be found in the supplementary material).

\subsection{Data collection}

A national representative survey among Danish farmers was conducted in 2013. The survey was administered by ASPECTO, a market research agency, with access to a panel of farmers. This data collection format was chosen to reduce costs and has been demonstrated to be as reliable as mail surveys in a Danish context (Olsen, 2009). ASPECTOs farmers' panel contained approximately 5.000 members. Danish farmers are familiar with reporting of farm management data on internet portals. Therefore, an internet-based study was not expected to reduce the representativeness of the sampled farmers. This is also supported by previous studies (Pedersen and Christensen, 2011), and enabled us to reach a large number and a broad range of Danish farmers. To increase the response rate, an IPad was offered as a prize to five randomly selected respondents.

The questionnaire was developed in dialog with advisors from SEGES (the Danish Knowledge Centre for Agriculture) and four individual farmers that acted as key informants. The draft questionnaire was then discussed in three farmer focus groups, and finally tested in a small pilot study. This process aimed to ensure that the final questionnaire was understandable, credible and relevant from the farmers' perspective. Respondents were asked a series of questions regarding their perception on climate change, expectation of the impacts they would incur, mitigation possibilities and their responsibilities towards adaptation and

\footnotetext{
${ }^{1}$ The authors have been in contact with SEGES; however they had no data or information regarding the sales of the certificates. It was not possible for the authors to obtain information from CelsiusPro.
} 
1 mitigation. Furthermore, socio-economic and farm information, such as type and number of

2 livestock, crop types, etc. were available from the farmer panel database. The list of socio economic and farm variables used in the final analysis are described in Table 1.

4 Table 1: Variables used in the choice experiment on farmers' insurance 5 adoption and their definition.

\begin{tabular}{|l|l|}
\hline Variable name & Definition \\
\hline No Effect & Expecting no effect of extreme events $(\mathrm{Yes}=1 ; \mathrm{No}=0)$ \\
\hline Inc. risk of loss & Expecting increase in crop loss (Yes $=1 ; \mathrm{No}=0)$ \\
\hline Adaption actions & The farmer is taking adaptive measures (Yes $=1 ; \mathrm{No}=0)$ \\
\hline Soil type & Soil type on the farm is predominantly clay $(\mathrm{Yes}=1 ; \mathrm{No}=0)$ \\
\hline Region Zealand & Farm located in the Zealand region (Yes $=1 ; \mathrm{No}=0)$ \\
\hline Owner & The farmer owns the farm (Yes $=1 ; \mathrm{No}=0)$ \\
\hline Experience & Farmer has experienced loss due to extreme events $(\mathrm{Yes}=1 ; \mathrm{No}=0)$ \\
\hline SoilQual & Soil quality (scale $1-5)$, where 1 is the best quality \\
\hline Arable & Farmer is an arable farmer ((Yes $=1 ; \mathrm{No}=0)$ \\
\hline Pigs & Farm produces pigs (Yes $=1 ; \mathrm{No}=0)$ \\
\hline
\end{tabular}

6

With a respond rate of $51 \%$ the survey resulted in 593 valid responses. A descriptive analysis shows that the sample is slightly skewed compared to the total population of farmers in Denmark. We find a typical bias: middle aged farmers are overrepresented, while young and older farmers are underrepresented. However, the geographically representation is fairly close to that of the total population of Danish farmers.

We use the variables listed in Table 1 to test the relationship between adoption of market insurance and propensity to invest in natural insurance (Table 2).

Table 2: Variables used to test alternative hypothesis about the link between climate change, agricultural adaptation behavior and adoption of insurance.

\begin{tabular}{|l|l|}
\hline Variable name & Hypothesized influence on insurance adoption \\
\hline No Effect & $\begin{array}{l}\text { We hypothesise that farmers who do not expect that the future climate } \\
\text { will lead to significant impacts will be less likely to purchase } \\
\text { insurance. }\end{array}$ \\
\hline Inc. risk of loss & $\begin{array}{l}\text { We hypothesise that farmers who are expecting and increase in crop } \\
\text { loss will be more likely to purchase insurance, everything else being } \\
\text { equal. }\end{array}$ \\
\hline Adaption actions & $\begin{array}{l}\text { Apriori, we do not know whether to expect that farmers who have } \\
\text { already undertaken adaptive measures are likely not to be interested in } \\
\text { insurance as they perceive that they have already taken adequate } \\
\text { measures. An alternative hypothesis could be that farmers who } \\
\text { undertake adaptive measures tend to me more concerned about future } \\
\text { impacts and therefore would be more likely to seek market insurance. }\end{array}$ \\
\hline Soil type & $\begin{array}{l}\text { We hypothesise that farmers with predominantly clay soil would be } \\
\text { more at risk of increasing precipitation. Therefore it would be }\end{array}$ \\
\hline
\end{tabular}




\begin{tabular}{|l|l|}
\hline Region Zealand & $\begin{array}{l}\text { expected that they would be more likely to insure, everything else } \\
\text { being equal. } \\
\text { The Zealand Region has a high Dexter ratio, which is the ration of } \\
\text { clay to soil organic carbon (Dexter et al., 2008). Soils with a high } \\
\text { Dexter ration are more likely to benefit from the prescribed } \\
\text { management practices than soils with a low index (Schjønning et al., } \\
\text { 2009). }\end{array}$ \\
\hline Owner & $\begin{array}{l}\text { It is anticipated that farmers who own their land will be more likely to } \\
\text { invest in sustainable soils as the effects of improved soil management } \\
\text { will only be realised in the longer term. }\end{array}$ \\
\hline Experience & $\begin{array}{l}\text { We hypothesise that farmers who have experienced loss due to } \\
\text { extreme events will be more likely to be interested in insurance. }\end{array}$ \\
\hline SoilQual & $\begin{array}{l}\text { We expect that soil quality could influence susceptibility of the crops } \\
\text { to adverse climate events and therefore potentially also influence the } \\
\text { likelihood of insurance uptake. } \\
\text { The farm type largely determine crops rotations and are therefore also } \\
\text { determining the sensitivity of the farm to climate events. The main } \\
\text { two categories of farm types are arable farms and livestock farms. } \\
\text { See above. Furthermore, pig farming is associated with cereal } \\
\text { production for feed, whereas dairy farming to larger extent rely on } \\
\text { grass for fodder. }\end{array}$ \\
\hline Arable & \multicolumn{2}{|c|}{} \\
\hline Pigs &
\end{tabular}

\subsection{An insurance scheme for Danish farmers}

3 In the survey, farmers who indicated that they could be interested in insuring crops against

4 adverse climatic events were given more information about the hypothetical insurance scheme.

5 They were presented with different versions of the insurance scheme via a choice experiment

6 (CE) design. Choice experiments belong to the family of stated preferences methods and use a

7 hypothetical setting (Hensher, Rose, \& Greene, 2005). In this study, the respondents were asked to choose the preferred of three alternatives in a choice set, one of the alternatives being the status quo (see Alpizar (2001) and Hensher (2004) among others for more information regarding choice experiment design). The other alternatives, i.e. "Insurance A" and "Insurance B" were a mixture of different levels of key insurance attributes. Setting up different versions of an insurance scheme enables analysis of farmers' preferences for insurances and of the potential trade-offs or synergies between the market insurance characteristics and the conditions to adopt appropriate soil management practices, which we here interpret as a longterm investment in natural insurance as a public good.

The insurance contracts were described based on the different attributes regarding forms of cover they offer, as well as on the extent, or level, of cover offered. Respondents were informed that the insurance scheme would be designed to prevent farmers from potential production loss due to heavy rainfall events. They were also informed that the compensation from the insurance 
1 scheme would be conditional on compliance with the soil sustainability standards set out in the contract involving reduced tillage and/or mulching of straw or plant residues. These measures were chosen based based on advice by the farm advisory services because they are believed to be effective and feasible in the context of Danish agriculture. Mulching is widespread, and broadly acknowledged as a method to increase soil organic carbon. However, it bears the opportunity cost of selling the mulch for example for bioenergy or livestock production. Reduced tillage is sometimes used to increase soil organic carbon although the effectiveness has not been widely proven (Zandersen et al. 2016). If the farmer already practiced reduced tillage or mulching prior to the introduciotn of the insurance scheme, those areas would also eligible for the insurance. Based on a review of crop insurance in Europe (see: Bielza et al., 2008 ), the insurance scheme could carry an annual premium between $3 \%$ and $9 \%$ of expected crop production in the insured area. In the event of a loss in production due to a heavy rain event, the insured would receive compensation for the full loss of agricultural production.

Two kinds of insurance schemes were offered to farmers as part of the CE: a yield insurance, in which loss and compensation is based on actual yield loss; and a weather/rainfall insurance, in which loss and compensation is based on local rainfall and with no excess, i.e. no deductions of the compensation payment. Both types of insurance would be governed by the Danish state, and implementation of specific soil sustainability measures would become conditional for being eligible for contracting insurance and being able to receive compensation payment in the event of the hazardous state occurring. The respondents were duly informed that the compliance with the contract would be monitored and enforced via a random selection of farms. Thus, the level of insurance premium, type of insurance, whether or not the farmer is requested to mulch, and/or applying reduced tilling are the four attributes used in the CE (see Table 2).

Table 3. Attributes and levels in the choice experiment model of farm insurance

\begin{tabular}{|l|l|}
\hline Attribute & Level \\
\hline Reduction of tilled area & $\begin{array}{l}10 \%, 25 \%, 50 \% \text { or } 75 \% \text {-for every 10 ha tilled today the farmer } \\
\text { will manage } 1,2.5,5 \text { or } 7.5 \text { ha with reduced tilling under the } \\
\text { contract. }\end{array}$ \\
\hline $\begin{array}{l}\text { Mulching of plant } \\
\text { residue }\end{array}$ & $\begin{array}{l}\text { Mulching of plant residues are (are not) required to insure the } \\
\text { farm. }\end{array}$ \\
\hline $\begin{array}{l}\text { Insurance type } \\
\text { Premium (\% of the } \\
\text { insured value) }\end{array}$ & $\begin{array}{l}\text { Yield insurance (with a 10\% excess) versus rainfall insurance } \\
\text { (with no excess) }\end{array}$ \\
$\begin{array}{l}3 \%, 5 \%, 7 \% \text { or } 9 \% \text { of the expected yield of crops on the insured } \\
\text { area. }\end{array}$ \\
\hline
\end{tabular}


1 Given the features of the insurance schemes, farmers could select one of the two insurance contracts or no contract at all. An efficient CE design, with conditions that avoid undesirable outcomes, was generated in NGENE (Choice Metrics, 2012). An efficient design does not only minimise the correlation in the data, but also aims to generate estimates with small standard errors (Choice Metrics, 2018). We used the parameter estimates from a small pilot with 30 farmers as prior information for generation of the design. We ended up with a design with eight choice cards per respondent. Each respondent was presented with eight different choice cards

8 (see example in Table 4).

Table 4 Example of an insurance choice card

\begin{tabular}{|c|c|c|c|}
\hline & Insurance $\mathbf{A}$ & Insurance B & No insurance \\
\hline $\begin{array}{l}\text { Reduction in tilled } \\
\text { area }\end{array}$ & $75 \%$ & $10 \%$ & \multirow{4}{*}{$\begin{array}{l}\text { I do not wish any of } \\
\text { the proposed } \\
\text { insurance } \\
\text { schemes }\end{array}$} \\
\hline Mulching required & No & Yes & \\
\hline Insurance type & Yield insurance & Rainfall insurance & \\
\hline $\begin{array}{l}\text { Premium (\% of } \\
\text { insured value) }\end{array}$ & $3 \%$ & $9 \%$ & \\
\hline $\begin{array}{l}\text { Choice (place an } X \\
\text { in the relevant box) }\end{array}$ & & & \\
\hline
\end{tabular}

\subsection{Model estimation}

13 We used a conditional logit model as a starting point for the analysis. Percent reduction of tilled area $(r t)$ and premium as a percentage of the insured value (prem) enter the model as linear variables. Mulching requirement $(m)$ and type of insurance scheme $(t)$ enter the model as effectcoded dummy variables. A respondent $(i)$ receives utility $\mathrm{U}_{j}$ when choosing one of the proposed alternatives. The probability that respondent $i$ will choose alternative $j(j=\mathrm{A}, \mathrm{B}$ or no contract) is equal to the probability that utility gained from choosing alternative $j$ is larger than or equal to the utility gained from choosing any of the other alternatives.

20 The utility model in a conditional logit model with an alternative specific constant specified 21 as:

$U_{A, B}=\beta_{p} r t+\beta_{m} m+\beta_{t} t+\beta_{\text {prem }}$ prem $+u_{A, B}$

24 where $u_{i}$ are error terms that are independently and identically distributed extreme values 25 (Gumbel-distributed) with variance $\pi^{2} / 6$ and a mean different from zero (Train, 2009). A 
1 potential status quo effect is captured by specifying an individual alternative specific constant

$2\left(\beta_{s q}\right)$ for the status quo utility.

3 Unobserved segmentation can be accounted for in a latent class model (Greene \& Hensher,

4 2003; Swait, 1994). This specification takes heterogeneity between individuals into account by

5 specifying underlying segmentation in the data set.

6 The utility function of the model with farmers belonging to latent class $\mathrm{s}=(1,2 . ., \mathrm{S})$ is:

$7 \quad U_{A, B \mid s}=\beta_{p_{s}} r t+\beta_{m_{s}} m+\beta_{t_{s}} t+\beta_{\text {prem }_{s}}$ prem $+u_{A, B \mid s}$

$9 \quad U_{s q \mid s}=\beta_{s q_{s}}+u_{s q \mid s}$

10 The subscript $s$ indicates individual preference coefficients in each class. The error term $11\left(u_{j \mid s}\right)$ is Gumbel distributed with variance $\pi^{2} / 6$ for each class. The number of classes that exist 12 in the data is decided using standard statistical measures (AIC, BIC and $\rho^{2}$ ) as guidelines, and 13 then the model results are taken into account before deciding on the final number of segments 14 (Boxall \& Adamowicz, 2002; Swait, 1994). Other specifications of heterogeneity could have been considered, such as e.g. mixed logit. Studies comparing the two (mixed logit and latent class) specifications have not come to a clear conclusion on which is the most preferred (Greene and Hensher 2003; Scarpa et al. 2005, Shen 2009 , Greene and Hensher 2013). Each of the specifications have their own advantages. The LC model is semi parametric, avoiding ad-hoc assumption about the distribution of parameters across respondents. The MXL allows for individual unobserved heterogeneity. Both specifications take the heterogeneity in the data into account. The LC model defines segments in the data to handle the heterogeneity, while the MXL is specified with random parameters. The advantage of the LC model is that it is possible to investigate the cause of the heterogeneity, and to explain the differences in the segments, which potentially have policy relevance.

The results from the conditional logit and the latent class models are used to estimate the farmers' expected willingness to pay (WTP) for the attributes in the insurance scheme. The WTP is defined by the marginal rate of substitution between the attribute and a payment - in this case the premium. 


\section{Results}

2

\begin{tabular}{|l|l|}
\hline Attributes & Parameter estimates \\
\hline Reduction in tilled area & $-0.427 * * *(0.034)$ \\
\hline Level of premium & $-0.155^{* * *}(0.017)$ \\
\hline Mulching & $-0.021(0.035)$ \\
\hline Insurance type & $-0.047(0.036)$ \\
\hline Status quo & $-0.696 * *(0.143)$ \\
\hline AIC & 4154.4 \\
\hline Log likelihood & -2072.21 \\
\hline
\end{tabular}

A standard conditional logit regression, with an alternative specific constant to account for possible status quo effect (Hensher et al., 2005) and the attributes given in Table 2 as explanatory variables, reveals that the respondents are indifferent to the mulching and insurance type (yield or rainfall) attributes of the insurance. We proceed with the modelling based on the statistical significant variables from the initial model specification. The utility model for insurance therefore looks like:

$U_{A, B}=\beta_{p} r t+\beta_{\text {prem }}$ Prem $+u_{A, B}$

$U_{s q}=\beta_{s q}+u_{s q}$

From the model it also appears that farmers prefer as few restrictions as possible as the tilling requirement reduces the attractiveness of the insurance contract, and farmers would prefer as low a premium as possible, as would be expected. However, the status quo is negative, indicating that they would become better off from having the insurance over and above what is captured in the scheme variables (Table 5).

Table 5. Insurance adoption parameters from the choice experiment

Note: $* * *, * *$ and $*$ are significant at $1 \%, 5 \%$ and $10 \%$ levels, respectively. Numbers in parenthesis, under the parameter estimates are the standard errors. Reduction in tilled area and premium are linear parameters. Mulching and insurance type are effect-coded parameters. Mulching $=1$ if the contract includes demand of mulching, if not mulching $=-1$. Rainfall insurance $($ index $)=1$; yield insurance $=-1$.

Other factors, such as socio-economic characteristics could also influence the respondents' choices. Therefore, the model is expanded to:

$U_{A, B}=\beta_{p} r t+\beta_{\text {prem }}$ Prem $+\beta_{\text {pigs }}$ Pigs $* r t+\beta_{\text {soil }}$ Soilqual $* r t+\beta_{\text {arable Arable }} * r t+$

$$
u_{A, B}
$$

$$
U_{s q}=\beta_{s q}+u_{s q}
$$


1 Table 6 (second column) shows the results of the conditional logit model including only the 2 statistically significant variables. Table 6 (third column) also shows results of the basic conditional logit model expanded by including the socio-economic variables interacted with the reduced-tilling variable. Scaling implies that care should be taken in analysing the estimation results directly. However, it is possible to focus on the interpretation of the sign of the coefficients, and their statistical significance. As expected, the coefficient for reduction in tilled area is negative, meaning that the larger an area the respondent needs to practice reduced tillage, the lower the utility derived from the insurance scheme. As expected too, the coefficient for the level of insurance premium is negative. The coefficient on pigs is negative, implying pig farmers are less willing to accept an insurance contract than other farmers. The reverse is the case for arable farmers. That was also expected, as pig farmers are less vulnerable to heavy rain than arable farmers. Interestingly, the coefficient for soil quality is positive, indicating that the lower the soil quality of the land in which the farmers operate, the higher the utility the farmers get from an insurance contract. The negative coefficient on the status quo indicator is statistically significant, realtively large and negative, indicating that on average farmers are interested in purchasing the insurance.

Table 6: Insurance adoption parameters for the conditional logit model (CLM), the CLM with interaction effects and the Latent Class model with two segments (1 and 2).

\begin{tabular}{|c|c|c|c|c|}
\hline \multirow[t]{2}{*}{ Attributes } & \multirow{2}{*}{$\begin{array}{l}\text { Base model } \\
\text { (CLM) }\end{array}$} & \multirow{2}{*}{$\begin{array}{l}\text { Expanded } \\
\text { model } \\
\text { (interaction) }\end{array}$} & \multicolumn{2}{|c|}{ Latent class } \\
\hline & & & 1 & 2 \\
\hline \multirow[t]{2}{*}{ Reduction in tilled area } & $-0.432 * * *$ & $-0.731 * * *$ & $-0.940 * * *$ & $-0.833 * * *$ \\
\hline & $(0.033)$ & $(0.092)$ & $(0.306)$ & $(0.171)$ \\
\hline \multirow[t]{2}{*}{ Premium } & $-0.156 * * *$ & $-0.156 * * *$ & $-0.366 * * *$ & $-0.123 * * *$ \\
\hline & $(0.017)$ & $(0.017)$ & $(0.052)$ & $(0.020)$ \\
\hline \multirow[t]{2}{*}{ Pigs } & & $-0.167 * * *$ & -0.168 & $-0.133 *$ \\
\hline & & $(0.041)$ & $(0.126)$ & $(0.075)$ \\
\hline \multirow[t]{2}{*}{ SoilQual } & & $0.060 * * *$ & $0.096 * *$ & $0.058^{*}$ \\
\hline & & $(0.018)$ & $(0.049)$ & $(0.034)$ \\
\hline \multirow[t]{2}{*}{ Arable } & & $0.084 * *$ & -0.068 & $0.147 * *$ \\
\hline & & $(0.033)$ & $(0.117)$ & $(0.066)$ \\
\hline \multirow[t]{2}{*}{ Status quo } & $-0.716 * * *$ & $-0.738 * * *$ & $-1.152 * * *$ & $-2.636 * * *$ \\
\hline & $(0.143)$ & $(0.143)$ & $(0.369)$ & $(0.197)$ \\
\hline \multirow[t]{2}{*}{$\begin{array}{l}\text { Membership Probability in the } \\
\text { Latent Classes }\end{array}$} & & & $0.640 * * *$ & $0.360 * * *$ \\
\hline & & & $(0.029)$ & $(0.029)$ \\
\hline AIC & 4152.5 & 4121.5 & \multicolumn{2}{|l|}{3066.6} \\
\hline Log likelihood & -2073.26 & -2054.73 & \multicolumn{2}{|l|}{-1520.29} \\
\hline
\end{tabular}


1 Note: $* * *, * *$ and $*$ are significant at $1 \%, 5 \%$ and $10 \%$ levels, respectively. Numbers in

2 parenthesis, under the parameter estimates are the standard errors.

3 Reduction in tilled area and insurance premium are linear parameters. Mulching and insurance 4 type are effect-coded parameters. Mulching $=1$ if the contract includes demand of mulching, 5 if not mulching $=-1$. Rainfall insurance (index) $=1$, yield insurance $=-1$. Pig and arable are 6 dummies that $=1$ if the farmer has pigs or grows crops. Soil quality is on a scale from 1 to 5 , 71 being the best quality and 5 being the worst quality.

9 In order to analyse if there is any relationship between farmers' preference' towards the 10 insurance scheme and expectations about the effect of future extreme weather events, a dummy variable was included, however this variable was non-significant, implying that those who believe they would be affected by future weather events would not have different preferences towards a hypothetical insurance scheme when compared to the rest of the respondents. This variable was thus not included in the reported results.

Besides the CLM, a latent class model (LCM) was estimated, where underlying segmentation of the sample is used. Following Swait (1994) and Boxall and Adamowicz (2002) the number of classes was determined by AIC, BIC and $\rho^{2}$ parameters as guidelines. Even though these information criteria indicated that more classes would generate a statistical improvement of the model, a two-class model was chosen, as models with more classes produced classes with only one significant parameter.

Since the LCM is a further specification of the CLM, the log likelihood values and AIC can be directly compared. The results suggest that the latent class specification is preferred. $64 \%$ of the respondents belong to segment 1 and $36 \%$ to segment 2 (see Table 6 for determinants segment membership). Both models have significant parameter estimates for reduction in tilled area, insurance premium, soil quality and status quo - and there is no shift in signs between the two segments. Segment 1 farmers place relatively large importance on the extent of the insurance premium, and their decision on whether they would purchase the insurce scheme depends more on soil quality than in the case of segment 2 farmers. In other words, the preference for insurance purchase depends mostly on a relatively low premium and the perception of working in farmland with a poor soil quality. Segment 2 is characterised by a large negative status quo estimate, indicating that farmers are interested in purchasing the insurance, and a significant effect for the type of farmer (pig or arable).

Table 7: Determinants of segment membership of the sample of farmers (for Segment 1)

\begin{tabular}{|l|l|}
\hline Variable & Parameters \\
\hline No effect & $-0.552^{* * *}(0.095)$ \\
\hline
\end{tabular}




\begin{tabular}{|l|l|}
\hline Inc. risk of loss & $-0.645^{* * *}(0.081)$ \\
\hline Adaptation actions & $0.001 * * *(0.000)$ \\
\hline Soil type & $-0.238^{* * *}(0.042)$ \\
\hline Region Zealand & $0.291^{* * *}(0.103)$ \\
\hline Owner & $2.635^{* * *}(0.195)$ \\
\hline Experience & $-1.055^{* * *}(0.202)$ \\
\hline SoilQual & $-0.129 * * *(0.028)$ \\
\hline Log likelihood & -4571.52 \\
\hline
\end{tabular}

1 Note: $* * *, * *$ and $*$ are significant at $1 \%, 5 \%$ and $10 \%$ levels, respectively. Numbers in 2 parenthesis, under the parameter estimates are the standard errors.

3 Soil type; Sandy $=1$, low and high activity clay $(\mathrm{LAC}$ and $\mathrm{HAC})=2$ and hummus $=3$, Zealand

$4=1$ (includes the region Capital and Zealand), rest of Denmark $=0$. Soil quality is on a scale

5 from 1 to 5,1 being the best quality and 5 being the worst.

7 Table 7 shows the results of an explanatory model that attempts to analyse what characterises farmers in segment 1. Farmers associated mostly with segment 1 tend to believe that more extreme weather will have an effect on their farming practices; however, they do not think the risk of productivity loss will increase as a result. Nor have they experienced productivity loss due to heavy rainfall in the past. They have taken action to prevent future losses and tend to own their farms; live in the Zealand region; have sandy soils and assess their soils as being of good quality. This would suggest that farmers with high quality soils, who believe that they have adapted their practices to the increasing risk and have not experienced productivity are less likely to invest in market insurance.

This finding is further confirmed by interpreting the WTP estimates for the different models and the individual segments (Table 8). The WTP represent the marginal rate of substitution between changing tilling practices and the insurance premium. The premium is a percentage of the expected yield of the insured area. The WTP is therefore also a percentage of the expected value of the insured area (Table 8). For the CLM model the results suggest that farmers are willing to increase their insurance payment (premium) by one $1 \%$ if they can reduce their adoption of reduced tillage by $2.77 \%$. Taking socio-economic variables into account seems to increase the MRS to 4.69\%. The results from the latent class model confirms the finding that segment two is more interested in adopting market insurance as they are willing to increase the area where they implement sustainable soil practices by $6.77 \%$ for a change in the insurance premium by $1 \%$, i.e. they are willing to pay more for insurance. In comparison, segment 1 is only willing to implement sustainable soil management on $2.57 \%$ their land. 
1 Table 8: Marginal rate of substitution between more sustainable soil management and 2 insurance.

\begin{tabular}{|l|l|l|l|l|}
\hline & $\begin{array}{l}\text { Base model } \\
(\text { CLM) }\end{array}$ & $\begin{array}{l}\text { Expanded } \\
\text { model }\end{array}$ & Latent class 1 & Latent Class 2 \\
\hline MRS & 2.77 & 4.69 & 2.57 & 6.77 \\
\hline
\end{tabular}

3

\section{Discussion}

5 It is clear from our analysis of Danish farmers' stated preferences that they are interested in

6 agricultural insurance to adapt to future extreme weather events. Farmers appear to be aware 7 of the future challenges and many are already adapting their practices to reduce their 8 vulnerability of their production sytem to expected adverse events. Implementing market insurance to mitigate income uncertainties could however create incentives to disinvestment in longer term sustainable land management. We have tested the prefermeces towards an insurance model that offers an opportunity for the government to mitigate the uncertainty related to moral hazard and social benefits from investing in natural insurance by making market insurance be conditional on sustainable soil management (via reduced tillage and mulching). Both practices have been proposed to improve soil structure and long term productivity and may also help manage soil organic carbon with clear societal benefits. The regulator therefore has a clear interest in the design of such schemes to utilise the opportunity to ensure provision of soil ecosystem services of a mixed private (for the individual farmers) and public goods. The two studied practices for providing natural insurance appears to generate different responses from the farmers. Most farmers (75\%) already perform mulching and this practice does not appear to be costly to the farmers. The cost of mulching is the loss of the alternative income from selling the mulch for energy production, minus the benefit of adding nutrients to the soil. Reduced tilling however, appear to be less favoured by farmers. The cost of having restrictions on tilling has, for most farmers, more unknown effects; they may have to learn how to manage the soil without ploughing and invest in new machinery to adapt their farming practice. Furthermore, the cost of weed control will probably go up, at least in the short-term.

The survey revealed that a majority of the farmers are already adapting to extreme weather events in order to minimise risks of production loss. Only $5 \%$ of those who experienced loss due to extreme weather did nothing to prevent future losses. This indicates that an insurance 
1 scheme could compliment how farmers choose to mitigate or adapt to climate change. In the interpretation of the results it is important to remember that the study reports on potential uptake of a hypothetical scheme. At the time of the data collection no real insurance scheme to cover against climate events were available to farmers. However, in August 2019, the Danish insurance company, TopDanmark, started to offer a yield insurance to Danish farmers. The insurance is available for cereal and oil seed rape and has an excess of $20 \%$. The premium is 19.4 euro/ha for cereal and 38.8 euro/ha for oil seed rape. The insurance pay-out is based on the loss relative to average years. The assessment of damage does not depend on a single event, but the sum of events over a year. The type of damage is not restricted to specific climatic events but could be damages caused by heavy rain, drought, insects, wild animals etc. The farmer is responsible for documenting the events that have caused the yield loss.

The insurance scheme differ in important ways from the scheme tested in the survey. Firstly, the premiums appear to be lower than the premiums in the hypothetical scenario and cover a wider range of damages. However, the cost of impact monitoring is the responsibility of the farmer and at this stage it is not clear what documentation will be required. Secondly, the new scheme does not appear to have any conditionality requirements and it is too early to analyse whether the implementation of the scheme will encourage less self-protection. However, as the payment is based on farm specific losses reported by farmers problems related to moral hazard would be expected. Thirdly, an excess was not included in the hypothetical scheme but is clearly a relevant scheme attribute in real insurance products. In future, it will be interesting to evaluate the attractiveness of the particular scheme using revealed data on insurance behavior and compensation levels.

The EU Common Agricultural Policy framework includes a compulsory risk mitigation component where member states are required to offer programmes for farmers to mitigate the risk to their business. This appears to offer an opportunity for Governments in the member states to align the need to mitigate risks to agricultural incomes while incentivising investment in nautral insurance for the longer term sustainability of agricultural production.

The main lesson from looking at Danish farmers' preferences towards insurance is that it appears plausible that farmers may be willing to accept a policy mix whereby governments may offer incentives to farmers to purchase market insurance (e.g, via subsidies to lower the price premium) while at the same time governments allowing (via regulation) access to subsidized insurance conditional on investing in soil management practices ("sticks"). In this 
1 way governments could mitigate the moral hazard of farmers disinvesting in natural insurance while helping them to insure against increased risks of crop failure due to climate change related extreme weather events, such as heavy rainfall. Farmers' preferences appear to support such carrot-stick approach. Of course, this result is based on a demand side analysis. We have not analysed the vibility of such combined insurance scheme from the private insurance supplier's perspective. It is likely that companies may play strategically and governments would thus also need to regulate the way companies design weather-related insurance products and the way they charge price premiums to different types of farmers so that governments' subsidies create additionality across different types of farmers in terms of their sustained investments in natural insurance.

\section{Conclusion}

12 The analysis of the insurance scheme reveals that market-based insurance has a demand in

13 Danish agriculture. The analysis also indicates a large heterogeneity between farmers and that the farmers most interested in insurance appear to be farmers with low quality soils, who have experience crop damages in the past. Furthermore, the analysis reveals that interest in insurance is dependent on the farming system as arable farmers tend to be more interested in buying insurance farmers than pig farmers. This was as expected, a priori, since arable farmers are more vulnerable to heavy rains than pig farmers, and farmers with poor soil quality run a greater risk of losing production because of adverse weather events.

The proposed scheme where natural insurance is a condition for participation in the marketed insurance schemes offers an opportunity for the regulator to reduce the risk that market insurance has unintended consequences for long term sustainability. The risk mitigation options under the CAP appears to offer an opportunity to implement the scheme in practice.

Acknowledgements: The paper was prepared under EU Framework 7 project "Ecological 27 Function and Biodiversity Indicators in European soils" (ECOFINDERS grant no. 264465). 28 Furthermore, the paper has benefited from support from the PREAR project (No 652615) 29 granted under the FACCE SURPLUS ERA-NET Cofund and funded by the Danish Innovation 30 Fund. 


\section{References}

ARMS (2010). Farm financial and crop production practices, USDA, Washington, D.C. Available online at: https://www.ers.usda.gov/data-products/arms-farm-financial-andcrop-production-practices/arms-data/

Alpizar, F. (2001). Using Choice Experiments for Non-Market Valuation. Retrieved from http://web.idrc.ca/uploads/user-S/10301141930choiceexperiments.pdf

Baumgärtner, S., \& Quaas, M. F. (2008). Agro-biodiversity as natural insurance and the development of financial insurance markets. Agrobiodiversity, Conservation and Economic Development, 293-317. Retrieved from www.uni-lueneburg.de/vwl/papers

Baumgärtner, S., \& Quaas, M. F. (2010). Managing increasing environmental risks through agrobiodiversity and agrienvironmental policies. Agricultural Economics, 41(5), 483496. doi:10.1111/j.1574-0862.2010.00460.x

Baumgärtner, S., \& Strunz, S. (2014). The economic insurance value of ecosystem resilience. Ecological Economics, 101, 21-32. doi:10.1016/j.ecolecon.2014.02.012

Becker, G. S., Isaac, E., \& Ehrlich, I. (1972). Market Insurance, Self-insurance, and SelfProtection. Journal of Political Economy, 80(4), 623-648.

Bielza, M., Conte, C. C., Dittmann, C., Gallego, J., Stroblmair, J., \& Strolblmair, J. (2008). Agricultural Insurance Schemes. European Commission. Retrieved from http://ec.europa.eu/agriculture/analysis/external/insurance/index_en.htm

Bouwer, L. M. (2019). Observed and projected impacts from extreme weather events: implications for loss and damage. Loss and Damage from Climate Change (pp. 63-82). Springer, Cham

Boxall, P. C., \& Adamowicz, W. L. (2002). Understanding Heterogeneous Preferences in Random Utility Models: A Latent Class Approach. Environmental and Resource Economics, 23(4), 421-446. doi:10.1023/A:1021351721619

Choice Metrics. (2012/2018). NGENE REFERENCE GUIDE The Cutting Edge in Experimental Design. Retrieved from http://www.choice-metrics.com/download.html

Ciscar, J. C., Fisher-Vanden, K., \& Lobell, D. B. (2018). Synthesis and Review: an intermethod comparison of climate change impacts on agriculture. Environmental Research Letters.

Crocker, T. D., Kask, S. B., \& Shogren, J. F. (1998). Valuing Ecosystems as Natural Insurance, (July).

Department of Agriculture, U. S. (2014). USDA Risk Management Agency. Retrieved from http://www.rma.usda.gov/ 
Dexter, A.R., Richard, G., Arrouays, D., Czyż, E.A., Jolivet, C., Duval, O., 2008.Complexed or-ganic matter controls soil physical properties. Geoderma 144 (3-4), 620-627.

Glauber, J. W. (2004). Crop Insurance Reconsidered. American Journal of Agricultural Economics, 86(5), 1179-1195.

Greene, W. H., \& Hensher, D. A. (2003). A latent class model for discrete choice analysis: contrasts with mixed logit. Transportation Research Part B: Methodological, 37(8), 681-698. Retrieved from http://www.sciencedirect.com/science/article/pii/S0191261502000462

Greene, W. H., \& Hensher, D. A. (2013). Revealing additional dimensions of preference heterogeneity in a latent class mixed multinomial logit model. Applied Economics, 45(14), 1897-1902.

Hazell, P., \& Skees, J. (2005). Insuring against bad weather recent thinking, (January). Retrieved from https://www.agriskmanagementforum.org/sites/agriskmanagementforum.org/files/Docu ments/Insuring Against Bad Weather.pdf

Hensher, D. A. (2004). Identifying the Influence of Stated Choice Design Dimensionality on Willingness to Pay for Travel Time Savings. Journal of Transport Economics and Policy, 38(3), 425-446.

Hensher, D. A., Rose, J. M., \& Greene, W. H. (2005). Applied Choice Analysis - a primer. Cambridge.

Horowitz, J. K., \& Lichtenberg, E. (1993). Moral Hazard, and Chemical Use in Agriculture. American Journal of Agricultural Economics, 75(4), 926-935.

Jensen, N., \& Barrett, C. (2017). Agricultural index insurance for development. Applied Economic Perspectives and Policy, 39(2), 199-219.

Linnerooth-Bayer, J., \& Mechler, R. (2015). Insurance for assisting adaptation to climate change in developing countries: a proposed strategy. Climate Change and Insurance (pp. 29-44). Routledge.

Mahul, O. (2001). Optimal insurance against climatic experince. American Journal of Agricultural Economics, 83(3), 593-604.

Miranda, M. J. (1991). Area-Yield Crop Insurance Reconsidered. American Journal of Agricultural Economics, 73(2), 233-242.

Miranda, M., \& Vedenov, D. V. (2001). Innovations in agricultural and natural disaster insurance. American Journal of Agricultural Economics, 83(3), 650-655.

Nganje, W. E., Hearne, R., Orth, M., \& Gustafson, C. (2004). Using Choice Experiments to Elicit Farmers Preferences' for Crop and Health Insurance. Retrieved from http://ageconsearch.umn.edu/bitstream/20357/1/sp04ng01.pdf 
Olsen SB (2009) Choosing Between Internet and Mail Survey Modes for Choice Experiment Surveys Considering Non-Market Goods. Environmental and Resource Economics 44(4):591-610. doi: 10.1007/s10640-009-9303-7

Paavola, J., Primmer, E. (forthcoming). Governing the provision of insurance value from ecosystems. Ecological Economics. This issue

Pascual, U., Termansen, M., Hedlund, K., Brussaard, L., Faber, J., Foudi, S., Lemanceau, P., Liv-Jørgensen, S. (2015). On the value of soil biodiversity and ecosystem services. Ecosystem Services 15:11-18

Pedersen, A. B., \& Christensen, T. (2011). Barrierer i landmændenes beslutningsmønstre vedrørende ændret pesticidanvendelse [Barriers in farmers' decision patterns of altered pesticide use], (134). Retrieved from http://www2.mst.dk/udgiv/publikationer/2011/11/978-87-92,779-18-2/978-8792,779-18-2.pdf

Quaas, M. F., \& Baumgärtner, S. (2008). Natural vs. financial insurance in the management of public-good ecosystems. Ecological Economics, 65(2), 397-406. doi:10.1016/j.ecolecon.2007.07.004

Rasmussen, S. (2008). Risikostyring i landbruget. Retrieved from http://www.nbi.ku.dk/english/staff/?pure=en/publications/risikostyring-ilandbruget(5b9164a0-a1c4-11dd-b6ae-000ea68e967b)/export.html

Santeramo, F. G., \& Ford Ramsey, A. (2017). Crop Insurance in the EU: Lessons and Caution from the US. EuroChoices, 16(3), 34-39

Schjønning, P., de Jongen, L.W., Olesen, J.E., Greve, M.H., (2009).Effekten af økologiskedriftsmetoder på ler-dispergering i kulstofudpinte jorde. ICROFS Nyt Nr4.

Shen, Junyi. (2009). Latent class model or mixed logit model? A comparison by transport mode choice data. Applied Economics. 41. 2915-2924.

Sherrick, B. J., Barry, P. J., Schnitkey, G. D., Ellinger, P. N., \& Wansink, B. (2003). Farmers' preferences for Crop Insurance Attributes. American Journal of Agricultural Economics, 25(2), 415-429.

Skees, J. R., Barnett, B. J., \& Murphy, A. G. (2007). Creating insurance markets for natural disaster risk in lower income countries: the potential role for Securitization. Agricultural Finance Review, Vol. 68 No. 1, pp. 151-167

Strunz, S. (2011, March). Ecosystem resilience as an economic insurance. Journal of Risk Research. Retrieved from http://www.tandfonline.com/doi/abs/10.1080/13669877.2011.634525

Strunz, S., \& Baumgärtner, S. (2010). Management of ecosystem resilience as optimal selfprotection : A simple, but often non-convex problem. Retrieved from http://www.bioecon-network.org/pages/12th_2010/Strunz.pdf 
Swait, J. (1994). A structural equation model of latent segmentation and product choice for cross-sectional revealed preference choice data. Journal of Retailing and Consumer Services, 1(2), 77-89. doi:10.1016/0969-6989(94)90002-7

Tadesse, M. A., Alfnes, F., Erenstein, O., \& Holden, S. T. (2017). Demand for a labor based drought insurance scheme in Ethiopia: a stated choice experiment approach. Agricultural Economics, 48(4), 501-511

Tadesse, M. A., Shiferaw, B. A., \& Erenstein, O. (2015). Weather index insurance for managing drought risk in smallholder agriculture: lessons and policy implications for sub-Saharan Africa. Agricultural and Food Economics, 3(1), 26

Taylor, M. (2016). Risky ventures: financial inclusion, risk management and the uncertain rise of index-based insurance. Risking Capitalism (pp. 237-266). Emerald Group Publishing Limited

Train, K. (2009). Discrete Choice Methods with simulation (second edi.). Cambridge.

Vogel, E., \& Meyer, R. (2018). Climate Change, Climate Extremes, and Global Food Production-Adaptation in the Agricultural Sector. Resilience (pp. 31-49)

Wood, B; Nielsen, HØ; Pedersen, AB; Kristofersson, DM (2017). Farmers' perception of climate change and their likely responses in danish agriculture. Land Use Policy,vol. 65:109-120

$\mathrm{Wu}$, J. (1999). Crop insurance, acreage decisions, and nonpoint-source pollution. American Journal of Agricultural Economics, 81(2), 305-320.

Zandersen, M; Jørgensen, SL; Nainggolan, D; Gyldenkærne, S; Winding, A; Greve, MH; Termansen, M. (2016) Potential and economic efficiency of using reduced tillage to mitigate climate effects in Danish agriculture. Ecological Economics, 123:14-22. 
Welcome to the survey.

The survey is about soil management and we would like to know more about your thoughts on soil management. We will ask you about your experience and attitude towards different cultivation methods. The study is funded by the University of Aarhus and will be used for a research project on sustainable soil management. Companies or organizations with financial, or political, interests in the results of the study have not contributed to the project. The aim is to investigate whether certain cultivation methods are attractive to farmers and under what conditions.

Please mark your gender:

Male:

Female:

Please note your birth year

Year:

What is your relation to the farm?

(please specify)

Owner/tenant with daily management

Owner/tenant without daily management

Employed with daily management

Employed without daily management

Other, please note:

How many hectares are cultivated (incl. leased area)

Number of hectares:

In the following, please give your answers with reference to this area

Are the agricultural land of the farm actively cultivated?

(please specify)

No, everything is permanent grass

Yes, the whole area is actively cultivated

Yes, part of the acreage is cultivated: hectares

If No, the whole area is permanent grass: STOP - "Thank you for your answers..."

Which of the descriptions below best describe you?

(please specify)

I am a full time farmer

I am a part-time farmer with other paid employment

I am a hobby farmer

Other, note: 
1 Who primarily decides on the management of the fields?

2 (please specify)

3

$4 \quad$ I decide everything myself (possibly with consultancy assistance)

5 I decide in consultation with others (eg employees, partners)

6 I do not even participate in the decision

What agricultural education do you have? (more answers possible)

9 (please specify)

11 Agricultural economist

12 Agronomist

13 Agriculture Technician

14 Farmer (The Green Proof)

15 Other, please note:

16 Does not have an agricultural education

17 Don't know / won't answer

In the following, we will ask if your production has been affected by major rainfalls in recent years.

To what extent have you observed areas that are water-logged?

(please specify)

In larger areas

To a limited extent

Not at all

Do not know

To what extent have you observed areas where the rainwater is not peculating through the

31 top-soil?

32 (please specify)

48 To what extent have you, in your own estimation, suffered a loss (of production) in

49 connection with the heavy rains in recent summers?

50 (please specify) 
2 Yes, significant loss

3 Yes, a minor loss

4 No, was not affected

5 Do not know

6

Filter 1:

9 If yes:

10 Are you actively doing something to secure your crops in order to avoid similar losses in the

11 future?

12 (It is OK to put more x's)

13

14 Yes, I have converted (parts of) the agricultural area to grass

15 Yes, I have changed the crop rotation

16 Yes, I have increased the supply of organic matter

17 Yes, I grow catch crops or the like. I.e. I have green fields in the winter.

18 Yes, I manage reduced tillage on all or part of the agricultural land

19 Yes, I repair / maintenance of drain

20 Yes, I have expanded the drainage area

21 Yes, I have invested in machinery

22 Yes Other

23

30 Yes, I have converted (parts of) the agricultural area to grass

31 Yes, I have changed the crop rotation

32 Yes, I have increased the supply of organic matter

33 Yes, I grow catch crops or the like. I.e. I have green fields in the winter.

34 Yes, I manage reduced tillage on all or part of the agricultural land

35 Yes, I repair / maintenance of drain

36 Yes, I have expanded the drainage area

37 Yes, I have invested in the machinery

38 Yes Other

\section{END Filter 1}

Have you experienced any other impacts on production due to weather incidents - in addition to erosion and problems with rainwater?

44 (It is OK to put more $\mathrm{x}$ 's)

$46 \quad$ No

47 Yes - which

Forecasts predict more extreme weather. How do you predict this will affect you? 
1 I don't think it's going to affect me

2 I will have to change crop

3 I have to take larger areas out of management

4 Increased risk of / frequency of harvest loss

5 Other things

6

In e.g. in the US and several European countries, it is possible to insure against losses caused by e.g. greater rainfall or drought with so-called crop insurance. Just as you have insurance in Denmark for hail damage.

10 Would you be interested in insurance against crop loss associated with e.g. precipitation?

11 Yes

12 No

13 Maybe if I knew more

The CE part is only asked if the answer the above question was Yes / Maybe

In the following, we would like to hear about your experience with certain cultivation methods

On how much of the arable land do you use organic fertilizer (ie slurry, manure ...)? On ha

On how much of the arable land do you mulch down straw or other plant residues? On ha

On how much of the arable land do you use sludge as fertilizer? On ha

On how much of the arable land do you grow catch crops? On ha

Reduced tillage means that the soil cannot be ploughed. In the transition to reduced tillage cultivation, the soil can become more compacted and increase the need for soil remediation. Over time this effect diminished as the soil structure is improved with root and earthworm channels. Mulching of straw and plant residues can also help the transition. Furthermore, by having a good crop rotation diseases and weeds can be minimized. The direct effect of reduced tillage can e.g. be seen on the number of earthworms, especially in the subsoil. In addition to the increased biological diversity in the soil, it has been shown that the soil structure will also be improved. This reduces the risk of both drought and water-logging. At the same time, the management will potentially sequester more carbon in the soil, thus reducing the atmospheric content of the greenhouse gas $\mathrm{CO} 2$.

Do you have experience with reduced tillage?

(please specify)

Yes - good

Yes - bad

Yes - both good and bad

No

Filter 2 


\section{If yes}

Do you manage with reduced tillage now?

Yes - all areas manage with reduced tillage

Yes - some areas are manage with reduced tillage

No - no areas are manage with reduced tillage

If some - on how many acres?

9 If no

10 Are you considering manage with no-till on all or part of the agricultural land?

11 Yes, I am considering it

12 No, not immediately

13 Do not know

14

Filter 2 is over

16

What could make you consider to try reduced tillage?

18 (please specify)

Economic compensation

21 Warranty for compensation in case of damage e.g. yield loss

22 More knowledge / information about reduced tillage

23 I don't want to practice reduced tillage

24 Other things:

In your opinion, what are the disadvantages of plow cultivation (It is OK to put more x's)

\section{Soil compaction}

Plant diseases overwinter

Necessary with crop rotation

31 Increased use of pesticides

32 Yield loss

33 It takes time before you can see a positive effect

34 Requires large financial investments in new machines, etc.

35 None

41 Financial savings (fewer man hours, less fuel)

42 It increases biodiversity in the soil

43 Increased yield

44 Good for heavy clay soil - saves engine power

45 Reduces the risk of flooding

46 None

Filter 3: If "reduced tillage" amounts to more than $75 \%$ or you have previously answered that 
Reduced tillage and mulching of straw or plant residues are examples of cultivation methods that can, among other things, contribute to improvements in soil structure and thus counteract erosion and water-logging. This is in the interests of both the farmer and the community - not least in light of the increasing problems with heavy rainfall in recent years.

Therefore, it is relevant to explore different options for offering cultivation methods that benefit the soil structure and soil quality in general. One possibility could be to offer insurance against crop losses - on the condition that the farmer could do something to reduce the losses, eg, reduced tillage. The principle is the same as when you lock the door - both for your own sake and because insurance requires it before you can get compensation.

In the following, you will be offered different versions of insurance. The insurances will insure you against any losses if, for example, greater rainfall. They will work as follows:

- You are obliged to cultivate the insured soil sustainably, in this case reduce tillage and / or mulching of straw or plant residues. Soil that is managed with reduced tillage in advance will also be covered.

- You pay an annual premium

- In case of "damage", you will receive compensation

- Payment of compensation is conditional on the cultivation of the land as stated in the contract. This will controlled by random sampling.

- There are two types of insurance Dividend Insurance and Precipitation Insurance

- Yield Insurance; Losses and damages are calculated based on your actual dividend. With dividend insurance, there is a deductible of $10 \%$.

- Rainfall Insurance; losses and damages are calculated on the basis of local precipitation data. There is no deductible.

- A government insurer is responsible for the offering.

In the table you can see the details of the insurance. On the next pages you can develop the box by clicking on the small button "click for more info."

\begin{tabular}{|l|l|}
\hline Attribute & Level \\
\hline Reduction of tilled area & $\begin{array}{l}10 \%, 25 \%, 50 \% \text { or } 75 \% \text { - that is for every } 10 \text { ha tilled today } \\
\text { the farmer will manage } 1,2.5,5 \text { or } 7.5 \text { ha with reduced tilling } \\
\text { under the contract. }\end{array}$ \\
\hline $\begin{array}{l}\text { Mulching of plant } \\
\text { residue }\end{array}$ & $\begin{array}{l}\text { Mulching of plant residues are/ are not required to insure the } \\
\text { farm. }\end{array}$ \\
\hline Insurance type & $\begin{array}{l}\text { Yield insurance (with a } 10 \% \text { excess) or rainfall insurance (with } \\
\text { no excess). }\end{array}$ \\
\hline $\begin{array}{l}\text { Premium (\% of the } \\
\text { insured value) }\end{array}$ & $\begin{array}{l}3 \%, 5 \%, 7 \% \text { or } 9 \% \text { of the expected yield of crops on the } \\
\text { insured area. }\end{array}$ \\
\hline
\end{tabular}

You will be presented with a choice between insurance A and B. If you do not find any of the insurance attractive, you also have the option to indicate that you do not want any of the insurance. 
1 You will be presented with this choice 8 times. Each time, the options will vary slightly. The 2 purpose is to find out which combinations of options might be attractive to you. The purpose 3 is not to test whether you respond according to your previous answers.

4 It is important that you consider each choice for yourself and that you try to take into account 5 all the conditions of the insurance.

6

Try to be as realistic as possible. Studies have shown that many people choose differently in questionnaires than in reality. Therefore, think carefully about your choices.

Example of one of the 8 choice card

\begin{tabular}{|c|c|c|c|}
\hline & Insurance A & Insurance B & No insurance \\
\hline Reduction in tilled area & $75 \%$ & $10 \%$ & \multirow{4}{*}{$\begin{array}{l}\text { I do not wish any } \\
\text { of the proposed } \\
\text { insurance } \\
\text { schemes }\end{array}$} \\
\hline Mulching required & No & Yes & \\
\hline Insurance type & Yield insurance & Rainfall insurance & \\
\hline $\begin{array}{l}\text { Premium (\% of insured value) } \\
\text { Choice (place an } X \text { in the } \\
\text { relevant box) }\end{array}$ & $3 \%$ & $9 \%$ & \\
\hline
\end{tabular}

13

14

15

16

Filter 4: If status quo in all 8 choice experiments

Why did you choose to continue without insurance in all the election situations? (tick 1)

I don't want to tie my production up on insurance

The deductible was too high

The premium was too high

It was unrealistic

There are already too many restrictions on how to grow one's land.

It was too difficult to choose

I do not want this kind of insurance

Other things

\section{End filter 4}

On a scale 1-5 how would you characterize your overall soil quality?

1 Healthy - good structure, very organic material and high biodiversity

2

3

4

5 Poor - poor structure, little organic matter and low biodiversity

Do not know

Which description best fits the way your land is part of the farm?

(please specify)

Production factor - an asset in my production

Investment factor - an investment in the future

Production and investment factor 
3 If investment factor / production and investment factor:

4 What do you do to nurture this investment:

5 Do not know

6

7 How do you see your role as a farmer in mitigating climate change?

8 Choose the statement that best suits you

9 I don't think I can make a difference

10 I feel that I am making an active effort to reduce the climate impact from agriculture

11 I wanted to make a bigger effort, but the cost of production is too high

12 I do not see it as my responsibility to reduce the climate impact

13 I do not believe in man-made effects on climate

14

30 If you have further comments, you can write them here: 